\title{
Ciudades literarias en el imaginario del norte chileno
}

\author{
Literary cities in Chilean North imaginary
}

\author{
Patricia Henríquez \\ Universidad de Concepción \\ pathenriquez@udec.cl \\ Mauricio Ostria \\ Universidad de Concepción \\ mostria@udec.cl
}

\section{Resumen}

La literatura ficcionaliza el espacio o lo convierte en escena: entran en juego los correlatos espaciales; los terrenos 'propios' y 'ajenos', cotidianos y sagrados, fantasmagóricos, oníricos. Se trata de espacios ficticios y sitios evocados capaces de simbolizar un conjunto de "lugares posibles" para el despliegue de un prodigioso imaginario geográfico. Así, en la narrativa nortina: las alturas andinas y sus pueblos de indios; los inmensos desiertos poblados de oficinas salitreras y faenas mineras; los veloces procesos de modernización urbana en puertos cuyos horizontes se tornan internacionales y transfronterizos. Estos lugares se hacen palabra y asumen el carácter de espacio nortino imaginario. De esa forma, el Norte Grande chileno ha sido asumido y transformado en sucesivos paisajes literarios en los que se reconocen el hombre y la mujer de esas tierras, como sucede concretamente aquí, en Pisagua y Pampa Unión.

Palabras clave: literatura chilena, novela nortina.

\begin{abstract}
Literature fictionalized space and turns it into scenes: spatial discourses come into play; owns and foreign lands, quotidian and sacred, phantasmagoric and oneiric fields. It is about fictional and recalled spaces capable to symbolize "possible places" combinations in order to unfold a prodigious geographic imaginary: Andeans altitudes and their Indian towns; huge deserts populated by salt mine office locations, the fast urban modernization process in ports whose horizons became internationals and cross-borders. These places turn into words and assume an imaginary northern character. With this, Chilean Big North has been assumed and transform into successive literary landscapes, in which men and women from this territory are recognized, specifically in this paper, from Pisagua and Pampa Unión.
\end{abstract}

Keywords: Chilean Literature, northern novel.

Recibido: $16 / 08 / 2021$

Aceptado: 02/11/2021 
La literatura ficcionaliza el espacio o lo convierte en escena, como el teatro. Asimismo, la fábula, el mundo de los personajes, la construcción del tiempo, la situación comunicacional y la ideología de la obra literaria son susceptibles de analizar como derivados respecto de la categoría fundamental de espacio, entendida esta como uno de los principios de organización de los diversos planos de la realidad presentada en los textos (Slawinski). Aquí, como en el teatro, entran en juego, por ejemplo, los correlatos espaciales de la práctica social; los terrenos 'propios' y 'ajenos', cotidianos y sagrados y hasta fantasmagóricos; los espacios de defensa y los espacios de conquista; las valoraciones y visiones de mundo representadas o simbolizadas en lugares, zonas, direcciones, puntos cardinales, regiones y fronteras, que se explican sobre la base de la mitología, la religión, las ideologías sociales, etc. (Bachelard, Foucault). Pero el espacio literario no solo se despliega en los estratos correspondientes a las objetividades representadas, sino también en la perspectiva de los sujetos y en la semántica y sintaxis de sus construcciones: en la literatura el espacio elemental y virtual es la página en blanco. La letra, la página, el libro pueden cobrar significaciones inusitadas en relación con el espacio: los casos del letrismo y los caligramas, de los libros ilustrados (dibujos, gráficos, fotografías, etc.) y de los libros-objeto (recuérdese el caso de Último round, de Julio Cortázar, estructurado físicamente en dos plantas, que pueden leerse separadas o complementariamente). Por último, no debe olvidarse el formato electrónico que permite un despliegue espacial a través de links, ventanas, hipertextos y otros recursos digitales virtuales.

Por otra parte, el espacio debe entenderse como móvil, cambiante, con puntos de vista múltiples (Cullen). En la literatura, el espacio que se crea entre el texto y el lector también se moviliza en la medida en que es condicionado por las diferentes perspectivas que puede asumir el acto de leer y la influencia de los contextos (históricos, sociales, culturales, etarios, de género, etc.). En estos devenires, los lugares y las estructuras que los sostienen, acotan y orientan su funcionalidad; son susceptibles de ser entendidos como textos o architextos culturales. Textos que como las culturas en que se integran, casi siempre son heterogéneos. En ellos es frecuente la contradicción, la inconsecuencia, la conjunción de estructuras diversas, de procedencias varias y cuyos sentidos cambian según las funciones que se les atribuyen. Esto origina la no uniformidad interna de los espacios semióticos. Es normal que en una cultura interactúen elementos heterogéneos y hasta disfuncionales. La combinación de tipos esencialmente diferentes de semiosis y, en consecuencia, el surgimiento de complejos problemas de recodificación, equivalencia, cambios en los puntos de vista y combinación de diferentes voces en un todo textual o en un conjunto de textualidades es particularmente notorio en los procesos de reciclaje, 
en las escenificaciones performáticas y en la novela. En esta última, la apariencia de un lenguaje natural, oculta una controversia compleja y contradictoria de diferentes mundos semióticos. (Lotman, Cornejo Polar) y propone, al mismo tiempo, negociaciones entre numerosos emisores y destinatarios (Bourriaud).

Aquí entendemos los diversos espacios como textos, en tanto todos ellos presentan una codificación o sistema que regula sus estructuras (funciones sintácticas, reglas de orden, disposición, función) y semánticas (designaciones, significados, sentidos, valores). En esa misma medida, son susceptibles de ser leídos. Son heterogéneas las relaciones entre diversas actividades simbólicas, en la medida en que se organizan según codificaciones, formas, materias, reglas y comportamientos disímiles; pero también en cuanto son el resultado de superposiciones y mezclas culturales. Asimismo, son heterogéneas las relaciones que se establecen internamente en cada uno de los campos: reunión, en un solo sitio, de varias versiones utópicas que son, a la vez, incompatibles entre sí (heterotopías). Es en ese aparente "desorden", donde los fragmentos de testimonios de diversas culturas adquieren múltiples sentidos.

\section{2}

Toda narración (épica, mítica, satírica, novelesca, legendaria, cuentística, etc.), en tanto relato imaginario, ficcionaliza un lugar: en ese proceso entran en juego, por ejemplo, los correlatos espaciales; los terrenos 'propios', ‘ajenos' y fronterizos;cotidianos y sagrados, fantasmagóricos, oníricos; los espacios de defensa y conquista; las valoraciones y visiones de mundo representadas o simbolizadas en territorios, zonas, direcciones, puntos cardinales, regiones y fronteras, centros y periferiasque se explican sobre la base de la mitología, la religión, las tradiciones y, claro, los procesos históricos y sociales. Se trata de espacios ficticios (creados por la palabra) y sitios evocados capaces de simbolizar "lugares posibles" propicios al despliegue de un prodigioso imaginario geográfico, utópico o heterotópico, siempre, hondamente humanizado.

La novela es un género esencialmente moderno, nace con el Renacimiento, y, en este sentido, está muy vinculada a las ciudades. Aunque estas aparecen tempranamente en la literatura. Así, por citar algunas famosas: Sodoma y Gomorra, en la Biblia; Troya, Ítaca, en los poemas homéricos; la Roma de la Eneida, Camelot (leyenda del rey Arturo), Pandemonium (El paraíso perdido, de Milton), Amaurota (Utopía, de T. Moro). Y entre nosotros: Aztlán (el mítico lugar previo de Tenochitlán), El Dorado (mítica ciudad que se creía ubicada en Nueva Granada), las siete ciudades de Cibola, (cuyas varias leyendas parecen tener su origen en la España musulmana 
y su concreción más famosa en relatos sobre la conquista española de América del Norte; La ciudad de los Césares, (que se suponía ubicada en un valle de los Andes), Trapalanda (la mítica ciudad de los náufragos españoles, en América). En la novela hay ciudades ficticias, como la ínsula Barataria (Don Quijote), Arkham (en las novelas de Lovecraft), Las ciudades invisibles (Ítalo Calvino), Minas Tirith (El señor de los anillos, de Tolkien). Y en la literatura infantil, Nunca Jamás (Peter Pan), el país de las maravillas (de Alicia), Ciudad Esmeralda (El mago de Oz), pero también algunas muy 'reales' como la isla de Robinson Crusoe. Un autor muy influyente en nuestra narrativa es, sin duda, William Faulkner, que situó muchas de sus novelas en el poblado imaginario de Yoknapatawpha County.

Entre nosotros, hay que mencionar, por lo menos, a Espelunco (Don Guillermo, de José V. Lastarria), Santa Mónica de los Venados (Los pasos perdidos, de Alejo Carpentier), Comala, (Pedro Páramo, de Juan Rulfo), Santa María de Neiva (El astillero, Juntacadáveres y La Vida Breve, de Juan Carlos Onetti), Macondo (Cien años de soledad, de García Márquez), El Olivo (El lugar sin límites, de José Donoso),sin olvidar, aunque se trate de relatos breves, la Ciudad de los Inmortales en los cuentos de Borges: “Tlön, Uqbar, Orbis'Tertius” y "El Inmortal”. Y, por supuesto el Aleph (ese lugar, reducido a un punto, síntesis de todos los espacios y todos los tiempos). También hay ciudades reales, obviamente, ficcionalizadas, en todas las novelas, como la Ciudad de México (La región más transparente, de Carlos Fuentes), Zapotlán (La feria, de Juan José Arreola), Lima (Conversación en la catedral, de Vargas Llosa), La Habana (Tres tristes tigres, de Cabrera Infante), o los sertoes de Guimaraes Rosa; Santa Teresa (Ciudad Juárez), en Los detectives salvajes y 2666, de R. Bolaño, sin olvidar a San Agustín de Tango (Santiago, en Ayer de Juan Emar) y a la misma capital de Chile, en las novelas de Blest Gana, Orrego Luco, Nicomedes Guzmán, González Vera, José Donoso, Diamela Eltit, Lina Meruane, Pedro Lemebel y tantas y tantas otras.

\section{3}

En la novela del Norte Grande, como en todo universo novelesco, se advierten diversas formas de yuxtaposición y fragmentación espacial, así como la existencia de espacios heterogéneos (zonas urbanas y rurales, fronterizas; paisajes montañosos, desérticos, marinos; espacios públicos y privados, centrales y marginales, interiores e íntimos, abiertos y cerrados, purificadores y ominosos, reales o simbólicos, míticos o fantásticos). También son observables en los diversos territorios, los procesos de modernización y desarrollo, así como los de deterioro y derruición, y, sobre todo, la ineludible interacción entre espacio y tiempo y entre ambos y los sujetos que se movilizan en sus coordenadas. 
Estos espacios abarcan tanto las alturas andinas y sus pueblos de indios, cuyas raíces culturales los vinculan sin interrupción a comunidades del sur peruano y boliviano y el nordeste argentino; los inmensos desiertos poblados de oficinas salitreras y faenas mineras; los veloces procesos de modernización urbana en puertos cuyos horizontes se tornan internacionales y transfronterizos. Tales lugares se hacen palabra (signo, símbolo) y en ese proceso se perspectivizan y asumen el carácter de espacio nortino imaginario.

En los años 30, Carnalavaca (1932), de A. Garafulic, ficcionaliza el mineral de cobre de Chuquicamata en sus inicios y en sus efectos no solo sobre el mundo andino, sino sobre toda la vida política y social del país. En tanto, en años recientes, Doris Araya, en Desde el abierto límite de la tierra de los chucos (1998) alude con nostalgia a los últimos días del mineral. Por su parte, Hugo Silva, en Pacha Pulai (1945) reconstruye fantásticamente, el viaje de un aviador perdido, el teniente Bello, hacia una ciudad del pasado colonial, oculta en la precordillera andina, nada menos que la Ciudad de los Césares. Los paisajes, leyendas y poblados precordilleranos son reconstruidos vivencialmente por el profesor, narrador y cronista Domingo Gómez Parra y el narrador calameño Héctor Pumarino Soto, en varios de sus relatos.

Los espacios pampinos, el desierto, las oficinas, las faenas mineras y sus efectos: explotación, conflictos, tragedias, sed, espejismos, extravíos, son narrativizadosa lo largo de la historia salitrera, entre 1830 y 1930 y hasta nuestros días. Desde Pisagua hasta Taltal fueron surgiendo gran cantidad de campamentos, oficinas y pequeños poblados que albergaban a los trabajadores y sus familias. Esos poblados perviven en novelas de entonces como de ahora. Y es precisamente en nuestro tiempo que han alcanzado dimensiones históricas y hasta legendarias. Tarapacá (1903), de Juanito Zolá, Eduardo Barrios, Baldomero Lillo, Carlos Pezoa Véliz, Víctor Domingo Silva, Luis González Zenteno, Mario Bahamonde, Andrés Sabella, Volodia Teilelboim, Nicolás Ferraro, Hernán Rivera Letelier, Carlos Franz, Francisco Mouat, Patricio Jara, etc.

La primera novela del Norte Grande parece ser Tarapacá (1903), ${ }^{1}$ de Juanito Zolá (seudónimo de Osvaldo López y Nicanor Polo), que narra el ambiente de pobreza en que viven los obreros, y la miseria moral de los acaudalados dueños de las salitreras, en la pampa y en Iquique, dos espacios estrechamente ligados por el boom del nitrato y, sin embargo, separados por el abismo de la opulencia y la

1 Cuya recuperación la debemos a las incesantes y fructíferas investigaciones del profesor y sociólogo de la Universidad Arturo Prat, Bernardo Guerrero Zamora. 
pobreza. Esa misma relación espacial y social se retoma en novelas como Rebelión en la pampa (1937), del alemán Theodor Plievier, Palomilla Brava (1943), de Víctor Domingo Silva; Norte Grande (1944), de Andrés Sabella; Hijo del salitre (1952) y La semilla en la arena (1956), de Volodia Teitelboim; Caliche (1954); y Los pampinos (1956),de Luis González Zenteno; La luz viene del mar (1963), de Nicomedes Guzmán y ya en nuestro días en las novelas de Hernán Rivera Letelier (La reina Isabel cantaba rancheras).

Por último, el surgimiento, apogeo y decadencia de ciudades costeras también es evocado en novelas y cuentos (Víctor D. Silva, Nicomedes Guzmán, Salvador Reyes, Andrés Sabella, Mario Bahamonde, Sady Zañartu y últimamente, Patricio Jara (Geología de un planeta desierto), Rodrigo Ramos (Ciudad berraca, etc.).

4

AI pie de este sol: semillería de piedras, colores que envenenan, muerte. iHe aqui la fotografía de la Pampa chilena! Y, Sin embargo, alli ha sido —y es_, la vida, el acento dominador. Vida que fue menester traer con el agua y al coraje, venciendo a la puna y a la sed, al acaso y al desengaño.

Andrés Sabella

El "infamado despoblado de Atacama" se fue poblando paulatinamente de gentes venidas de todas partes del mundo. Así, en la efímera vida salitrera fueron apareciendo pequeños pueblos o ciudades que dieron fisonomía humana al desierto. Aquí, nos referiremos a dos de ellos que, por diversas razones, adquirieron prestigios positivos y/o negativos, heroicos o divertidos, ominosos o trágicos (a veces todo junto) y que fueron exitosamente ficcionalizados: Pisagua y Pampa Unión: ambos siguen hablándonos desde la recreación literaria y se constituyen en un rico legado cultural del Norte, a pesar de su miserable o ruinosa condición actual. 


\section{1}

Diálogo de Chile

Verás un mar de piedras

Verás margaritas en el mar

Verás un Dios de hambre

Verás el hambre

Verás figuras como flores

Verás un desierto

Verás el mar en el desierto

Verás tu odio

Verás un país de sed

Verás acantilados de agua

Verás nombres en fuga

Verás la sed

Y llorarás

Raúl Zurita

Pisagua es una pequeña localidad chilena, ubicada en la costa, entre Iquique y Arica. En el caserío, semiabandonado, viven hoy en día unos 300 habitantes. Hasta la Guerra del Pacífico, Pisagua perteneció al Perú. Durante la primera mitad del siglo XIX, sus pobladores explotaron las guaneras allí existentes. Esto permitió que la ciudad se transformase en una importante localidad del sur peruano, a pesar del terremoto del 13 de agosto de 1868, que arrasó la población. En 1870, fue declarada puerto mayor por el Gobierno del Perú. Entonces, su principal actividad económica era la minería, especialmente el nitrato y el yodo. Al iniciarse la Guerra del Pacífico, las tropas chilenas desembarcan en Pisagua (2 de noviembre de 1879), tomando posesión de ella. Así, se da comienzo a la campaña terrestre de la guerra en territorio peruano. La operación culminó con la ocupación de Pisagua, pese a la decidida defensa de los aliados (Perú y Bolivia), en la que murieron unos 350 bolivianos, peruanos y chilenos. Ya en el siglo XX, Pisagua fue un importante puerto para el embarque y la exportación de nitrato durante el auge salitrero industrial que se vivió en el norte de Chile hasta los años treinta del siglo pasado. Hacia 1900 contaba con modernos muelles con grúas mecánicas, un activo movimiento portuario, aduana, oficina del Registro Civil, algunos bancos, diversas casas comerciales chilenas y extranjeras, un teatro (donde llegaron a cantar destacadas figuras del canto lírico), algunos hoteles y consulados foráneos, una parroquia, una escuela fiscal, un cuartel de bomberos, un hospital y todos los servicios urbanos propios de una ciudad de la época, incluidos un servicio de tranvías urbanos, teléfonos y energía eléctrica, así como cable submarino y telégrafo. Con cerca de 10.000 habitantes, 
Pisagua se convirtió en una de las ciudades más bellas de la árida costa nortina y uno de sus puertos más importantes. Tras el fin del auge salitrero, Pisagua mantuvo cierta importancia debido a la explotación pesquera; pero, a fines de los años cincuenta del pasado siglo, la zona urbana decayó ostensiblemente hasta convertirse en el caserío que es hoy.

Pero Pisagua carga, asimismo, con una lastimosa fama, convertida en escritura: ha servido de escenario a tristes y lamentables sucesos, constituyéndose en un espacio ominoso, signado por el sufrimiento y la muerte. A esto hay que añadir su ubicación geográfica a orillas del desierto, lo cual, por decirlo así, multiplica su triste fama. En efecto, horribles episodios históricos han venido a cargar al desierto con un oscuro prestigio en tanto espacio destinado a convertirse en campo de prisioneros políticos. Esta visión negativa refluye sobre Pisagua y la convierte en símbolo de lo ominoso y de la muerte: "cementerio" la llama Alcides Arguedas; "pueblo fallecido", Volodia Teitelboim.

El desembarque de las tropas chilenas en la Guerra del Pacífico y los horrores vividos en el campo de prisioneros establecido por el gobierno de González Videla impulsan a dos destacados escritores, uno boliviano, Alcides Arguedas, y otro, chileno, Volodia Teitelboim, a escribir sendas novelas con el título de Pisagua. Arguedas es conocido, sobre todo, por su novela Raza de bronce (1919), pionera del indigenismo literario andino y por Pueblo enfermo (1904), un ensayo en que caracteriza el proceso histórico y social de Bolivia con las tintas más oscuras. Teitelboim, por su parte, es coautor de la polémica Antología de la poesía chilena nueva (1935) y de dos novelas ambientadas en el Norte Grande: Hijo del salitre (1952) y La semilla en la arena (1957). Mientras Arguedas halla en Pisagua el escenario propicio para la inmolación de su protagonista, justo el día del desembarque de las tropas chilenas, Teitelboim rememora sus propios sufrimientos y los de sus compañeros en la Pisagua convertida en campo de prisioneros.

Alcides Arguedas nace en La Paz, justamente, el año de inicio de la Guerra del Pacífico y la inclusión del episodio del desembarque chileno en Pisagua no parece gratuito. Arguedas pertenece a la llamada generación mundonovista, es decir, la del grupo de escritores que reacciona en contra del modernismo dariano y procura construir una literatura más cercana a la tierra, provisto de las herramientas del naturalismo literario y al positivismo filosófico. Su visión, en general, pesimista, está marcada por las ideas básicas del determinismo comptiano: herencia, geografía y condiciones históricas. Armado con tales conceptos, Arguedas, que es también uno de los grandes historiadores de Bolivia, interpreta la realidad de su país, marcada desde la conquista por el mestizaje y la violencia social, rasgos negativos 
y fatalistas. Su novela Pisagua, la primera que escribe, publicada en 1903, a los 24 años de edad, busca relacionar dos hechos históricos: la revolución que derroca al tirano Melgarejo, en 1871 (que abre el relato) y el desembarque chileno en Pisagua, con que se inicia la Guerra del Pacífico, en 1879, que lo cierra. El gran gozne que une ambos episodios es la historia del protagonista, Alejandro Villarino, un intelectual, idealista y romántico, con tendencia al suicidio, signado por la fatalidad, que participa heroicamente en ellos y que acaba sus días inmolado en el combate de Pisagua. "Pisagua — escribe Arguedas_ quiso ser un canto épico. En torno a una descolorida aventura sentimental intenté describir dos episodios ya justamente legendarios: el valor y la abnegación de la raza puestos a prueba de muerte en un trance desesperado" (La Danza de las sombras 632). Arguedas no conocía Pisagua ni tampoco el mar al escribir su novela; solo un tiempo después, de paso en Antofagasta y rumbo a España, el escritor boliviano dejaría, como al pasar, esta breve imagen del mar recién descubierto por sus ojos asombrados y su visión siempre pesimista: "el espectáculo del mar me hizo concebir pasajeramente la idea de la pequeñez de los hombres" (La Danza de las sombras 633).

La literatura no se nutre necesariamente de la experiencia vivida. Así, una de las más convincentes descripciones de la pampa argentina es la de Sarmiento, en su Facundo, hecha con la imaginación y los libros. Del mismo modo, la imagen del puerto de Pisagua que nos entrega Arguedas, sin conocerlo es notable:

Figuraos un formidable exabrupto desgarramiento de la costa avanzando hacia el mar en forma de herraje lleno de arrugas, ondulaciones y asperosidades y en medio una ciudad pequeña y cuyas calles, trazadas a cordel, van a chocar, unas contra la escarpada pendiente de la costa, cual si quisieran escalarla, y otras a perderse en la inclinación del terreno que se precipita por medio de gradientes y sinuosidades a la playa defendida en unos puntos por peñascos cortados a pico, y en otros por grupos de rocas esparcidas acá y allá y que semejan los restos de un edificio monstruo destruido quién sabe por qué cataclismos. . . ciudad triste como un cementerio y en la que, si algo se oye, es el rugido del océano que se retuerce con furor de fiera enjaulada, y de vez en cuando el silbido de la locomotora cuyos rieles suben ceteando el cerro hasta llegar a la cima donde se extiende la pampa de horizontes vastos y sin más miraje que un cielo casi constantemente azul, de una monotonía cargada de nostalgias, un mar verdoso que golpea sus muros de granito y una naturaleza desnuda y árida como el vientre de una momia (Pisagua 76). 
El episodio de Pisagua ocupa solo el último libro (capítulo) de los seis que componen la novela, unas 10 páginas. Lo más significativo, desde el punto de vista simbólico, es el valor negativo y funesto que se asigna al mar, el que parece, en todo momento, estar en contra de los defensores de Pisagua y a favor de los invasores: "El mar, tranquilo hasta entonces, comenzaba a irritarse, dando golpes sobre las rocas donde estaban encubiertos los bolivianos"(Pisagua 81). Del mismo modo, es muy significativo — en toda la novela - el valor de anticipación funesta que se asigna al crepúsculo. Precisamente, el sacrificio inútil de Villarino, su trágico héroe, se consuma "en las refracciones que el sol poniente levantaba de las olas" (Pisagua 85).

Volodia Teitelboim nace en Chillán, en 1916 y pertenece, por lo tanto, a la generación neorrealista o generación de 1938, que se aglutina en torno a los ideales del Frente Popular, y asume una actitud —equivalente a la generación de Arguedasde rechazo tanto al cosmopolitismo dominante en los escritores vanguardistas, como al localismo criollista y busca un mayor afincamiento en la problemática popular y social; pero, a la vez, con una clara idea de la construcción artística con proyección universal. Su novela Pisagua, fue publicada por primera vez en 1957, con el título de La semilla en la arena. Allí se narran las desventuras de cientos de chilenos, hombres y mujeres, relegados al puerto nortino, en calidad de prisioneros políticos. La novela narra desde la llegada de los primeros contingentes, sus diversas peripecias, angustias, precariedades, intentos de fuga, aventuras amorosas y picarescas, esfuerzos por organizarse socialmente en procura de una vida digna hasta el esperanzador momento del regreso. A diferencia de Arguedas, Teitelboim si conoció Pisagua y muy de cerca: él fue uno de los desterrados que vivió en carne propia la condición de prisionero político de modo que, aunque no queda de manifiesto en la estructura narrativa de la novela, la perspectiva autorial es la del testigo. El paisaje de Pisagua en la novela de Teitelboim es el espacio presente desde que se abre el relato hasta su final (incluso, la tercera parte prolonga el territorio hacia los Andes) y se inscribe en la visión nostalgiosa y defectiva con que el habitante del sur, el relegado, contempla la tierra árida y soleada del Norte:

Margarita tornó a contemplar obsedida el paisaje y las ruinas. Como la mayoría de aquellos involuntarios viajeros. . . ella veía por primera vez el desierto. . . el mundo había perdido aquí su rostro verde, el alma casi humana que ella se había acostumbrado a percibir en su tierra de Lota, rodeada de bosques y brillante de clorofila. Aquí el hombre parecía un extraño, y vivirían doblemente deportados de la libertad y la fertilidad, entre la soledad y los peñascos. Ella era mujer de lluvia, del perfume de las araucarias, de tomar gotas de resina en los dedos, y aquí no había lluvia ni pinares, ni caminos para la libertad (Teitelboim 19). 
Esta doble privación (libertad y fertilidad) marcará la vida de los prisioneros durantetoda su permanencia en el aciago puerto nortino; es decir, durante todo el relato. Carencia multiplicada por las condiciones de abandono y derruición en que se hallaba la ciudad:

Era una abandonada sombra, un pueblo fallecido hace tiempo, insepulto tal vez por negligencia, error o espíritu de ficción, agazapado en un minúsculo terraplén del macizo costeño. Al pie de esos descoloridos montes, surcados por franjas leonadas, en la lonja estrecha, al fondo del agujero, ella y los suyos iban a pasar no sabía cuántos días, meses o años de su vida. Al comprobarlo como algo inevitable sintió un estremecimiento (18).

Así, mientras para Arguedas, el espectacular espacio pisagüino, sitio entre el océano y el desierto, en cuya garganta flanqueada de rocas se yergue la ciudad, semejante a un cementerio, funciona solo como un escenario eventual, propicio al desenlace trágico y al inútil sacrificio de su héroe; para Teitelboim, en cambio, ese mismo espacio, del que es casi imposible huir, se constituye en cárcel, donde los prisioneros procurarán hacer del pueblo muerto un lugar donde volvería a brotar porfiadamente la vida. Ciertamente, ambas visiones, contrapuestas, están signadas no solo por las experiencias personales de los autores (el conocimiento sobre Pisagua), las condiciones históricas (guerra del Pacífico, campo de prisioneros) que determinan la configuración del lugar y el sentido de los hechos, sino también por el trasfondo ideológico que amplía y proyecta ese sentido a una cosmovisión que determina el sistema de posibilidades de las novelas. Para Arguedas el sacrificio (individual y colectivo) es inútil no solo porque el enemigo logró desembarcar en Pisagua y, finalmente, la guerra se perdió, sino porque, habida cuenta de su formación intelectual, el proceso social de Bolivia, desde su perspectiva, parece estar condenado al fracaso. Para Teiltelboim, en cambio, la condición de prisioneros en una cárcel incluso natural — “. . . casi de inmediato pensó en la fuga. Pero si intentaban huir se estrellarían contra el árido peñón de la cordillera de la Costa o se hundirían. . . en la muralla horizontal del mar, a menos que escaparan por el cielo. Mas el cielo ¿acaso no era, aunque pintado de azul, una de las tres puertas cerradas de esa tórrida cárcel natural?” (Teitelboim 19)—; no es signo de verdadera tragedia: su creencia en el poder del pueblo para sobreponerse, está inspirado en el humanismo marxista. Por eso la novela termina con esta imagen, reveladora del estado de espíritu de quienes han sido liberados: "El mar ahora centellea en la luz nocturna. A bordo se hace el silencio del corazón colmado. Aunque la nave parece inmóvil, ellos saben que avanzan, pues ¿acaso los hombres no van en el movimien- 
to infinito? La oscuridad ya se ha hecho plena, pero en el barco todo se ve tan claro como si transportara una antorcha" (Teitelboim 477).

Muchos años más tarde, Sergio Missana (1966) construye una novela - Movi-miento falso (2000) - que incluye aspectos de relato de viaje y de aprendizaje y, sobre todo, de novela negra, que, no obstante, adquiere su densidad en la relación ambigua de los personajes, siempre huidizos y en la permanente presencia de un espacio inseguro en el que se confabulan el desierto, las ruinas, los lugares tenebrosos y la historia terrible. Véase, por ejemplo:

Lo asaltó la tentación de preguntarle a ese hombre si conocía a Brown. Aquello hubiera significado delatarse, cortar cualquier posibilidad de acercamiento, si no se había marchado ya de ese lugar ominoso. Tarde o temprano terminaría por enterarse de que alguien lo había estado buscando. Eso significaba, pensó, llevar el asunto de golpe hasta sus últimas consecuencias. Después de eso solo quedaría absorber lo que la gente del pueblo quisiera informarle sobre el tío de Irene y largarse de allí sin más demora. En caso de que Brown fuera el verdadero objetivo para haberse dirigido hasta allí, lo que no estaba claro en absoluto (Missana 63).

Para el posmoderno Sergio Missana, la incertidumbre de la historia y hasta de la propia libertad y, claro, el prestigio ominoso de Pisagua, presente en cada esquina, en cada rincón, en cada sujeto del lugar, proyectan en su aproblemadopersonaje "una Inexplicable sensación de desamparo".

Así, decididamente, en las tres novelas, Pisagua se yergue como un personaje mudo e inquietante, devastador y devastado, cárcel natural, presencia ambigua de sombras y luces que instalan un cúmulo de incertezas e incertidumbres.

4.2

\begin{abstract}
Carcomido el silencio, carcomido hasta el aire de rostro solitario. Veo correr la sombra de otros niños con la muerte gloriosa en sus harapos.
\end{abstract}

Andrés Sabella

Pampa Unión, sin ser propiamente una oficina salitrera, fue el poblado más importante de la pampa, llegando a contar con más de 5.000 habitantes permanentes. Dada la gran cantidad de heridos y enfermos que se producían en las faenas mineras, se intentó crear, en 1911, un hospital cercano a las oficinas y al ferrocarril. Tras la construcción del sanatorio, Pampa Unión se transformó, rápidamente, en 
un centro de entretención y comercio, llegando a ser el único pueblo libre de toda la comarca. Los fines de semana se colmaba de pampinos deseosos de comprar diversas vituallas y, sobre todo, pasarlo bien, gastando sus salarios en comidas, bebidas y, especialmente, en prostíbulos. Varios narradores y poetas nortinos han evocado, con nostalgia y picardía el auge pasado del Pampa Unión de los años 20 del siglo pasado. En esta ocasión, nos referiremos, especialmente, a las visiones e imágenes de Pampa Unión y sus diversas funciones como espacio heterogéneo y multicultural en dos novelas de autores nortinos, Terral (1959), de Nicolás Ferraro y Fatamorgana de amor con banda de música (1999), de Hernán Rivera Letelier.

Nicolás Ferraro (1921-2012) nació y vivió su infancia en Pampa Unión y la pampa lo marcó para siempre. A través de sus relatos y poemas, Ferraro pone en relación un conjunto de rasgos que permiten vislumbrar, sin grandes estridencias, pero con verdad estética y antropológica, una visión convincente, persuasiva y conmovedora del habitante del norte, especialmente, de la pampa y de la puna. Desde la naturalidad de los gestos cotidianos hasta la evocación mítica y legendaria del indio atacameño, la escritura de Ferraro se construye como un continuo gesto de adhesión a los ancestros en medio de un hábitat desolado y triste, pero cargado de querencias. Mientras sus versos resuman amor raigal y adhesión incondicional por su desierto, al que le atribuye los poderes del agua: “Tierra mía de espanto, triste, inerme; / océano de fuego, mar de arena; / he de volver hasta tu seca vena / para reverdecerme” (21), y por su pueblo: “ipor ahí anduvo mi infancia! / Entre estas piedras rotas, secas / tan espantosamente muertas. / Horriblemente abandonadas. / Casas que son tres muros sueltos, / el ojo abierto de alguna ventana / y una puerta deshecha que ni el viento / golpea cuando pasa. / Por aquí, os lo digo con angustia, / creció mi infancia. .." (Tierra Amor, "El regreso y la furia").

Sus relatos trasmiten imágenes persuasivas de la agonía y muerte de los pueblos salitreros, con los que, sin duda, el narrador se siente involucrado: "cerrando los ojos para evitar la resolana uno puede percibir. . algunos muros derruidos donde el viejo viento se estrelló llorando. El aire caliente da un aspecto terrible a lo que ya es terrible y solo. Deforma las perspectivas. Brilla todo con furia. Hay espejismos; lagos de agua pura y helada, castillos, embarcaciones y muchachas, ciudades. Enloquecemos bajo el sol amarillo e implacable (Terral 12).

La novela Terral ('viento de tierra'), premiada por la Sociedad de Escritores de Chile, es apenas conocida. La acción, una historia de soledad y amor frustrado se sitúa, aunque no se dice explícitamente, en Pampa Unión, en ese entonces, un pequeño caserío con alguna tienda de ropa, alguna hospedería, cantinas, tugurios de juego, prostíbulos y modestas viviendas. La historia está contada en primera 
persona autobiográfica: es Pedrín, un muchacho, dependiente de la tienda de José Árbol que cuenta sus aventuras y desventuras en el pueblo que termina por abandonar. Terral narra soledades y lecturas, afectos y pendencias, amores y amoríos, pero, sobre todo soledades, mientras "la tienda permanece vacía en medio del calor caliginoso de la tarde y afuera el viento corre empujando polvo hacia una lejanía desolada y árida" (10). Todo en un dominante tono elegíaco.

Sin duda, Hernán Rivera Letelier es el novelista más popular, más representativo y prolífero que ha producido el Norte Grande, específicamente, el desierto y la región salitrera. Como tantos sureños devenidos en pampinos, Rivera Letelier nació en Talca, pero creció en tres oficinas salitreras: Algorta, María Elena y Pedro de Valdivia, con un intervalo en Antofagasta. Después de un viaje por algunos países de Sudamérica, vuelve a la pampa y empieza a escribir. En 1994, publica, con gran éxito, su primera novela: La reina Isabel cantaba rancheras a la que seguirán muchas más hasta la actualidad.

Fatamorgana de amor con banda de música (1998) es la novela de Pampa Unión: narra el apogeo y repentina destrucción, con caracteres apocalípticos, del 'único pueblo libre' de la pampa. Con ocasión de una anunciada visita del presidente de la República al lugar, se prepara una fiesta "en este ignorado pueblo de boliches y burdeles. Para unos será la nueva cita del amor perdido, para otros, la esperanza de cancelar su miseria, para algunos, la oportunidad del tiranicidio". Pero para todos será un espejismo, un engaño, es decir una fatamorgana: el presidente no se baja del tren en Pampa Unión, y el amor y las esperanzas concluyen en la muerte, en la nada.

La acción de la novela se sitúa en una Pampa Unión progresista y llena de vida. Recuerda un personaje: "Para ese entonces Pampa Unión ya no era ese pequeño caserío de comercio desordenado de cuando él llegó a instalarse con su taller, cuando el alumbrado público todavía funcionaba con faroles de parafina y las calles aún no tenían nombre, y la gente llamaba Calle del Comercio a la calle principal y Calle de las Putas a la calle de atrás, donde funcionaban la mayoría de los prostíbulos que habían dotado al pueblo de su legendaria aura de mala fama" (20). En verdad, Pampa Unión "había llegado a ser el pueblo más combatido y vituperado que jamás haya llegado a existir por estas perdidas comarcas de Dios. Un pueblo blanco de intrigas por parte de los dueños de las salitreras que, entre otros epítetos de ignominia, lo habían catalogado - desde los editoriales de los periódicos comprados por los mismos magnates - de infernal antro del vicio, vil centro de corrupción y pernicioso burdel del desierto. Y que, por lo mismo, pese a sus años de ardua existencia, todavía el Estado no se dignaba a reconocerlo legalmente" (48). Así, en medio de una atmósfera de farsa carnavalesca, "en cada fin de semana, toda la 
población salitrera del Cantón Central se trasladaba en masa a divertirse(48)" al único pueblo libre del entorno: "deslumbrante y tembloroso como el espejismo de un ave del paraíso en pleno desierto. . . (48)".Aunque "el paisaje seguía siendo el mismo peladero de planeta recalentado(XX)", "Contemplar el amanecer en el desierto era como asomarse el primer día de un planeta recién creado (55)"; mientras "en las tardes más plácidas. ., arreciaban de pronto remolinos de proporciones gigantescas (los terrales tarderos) que se tomaban al pueblo por asalto, estropeaban los techos, se llevaban las cañas y dejaban todas las cosas del mundo espolvoreadas de la salobre arena del desierto (64). Así y todo, "el pueblo de Pampa Unión seguía igual de vivo y alegre" (70): "se había desatado un gran carnaval de challa. La calle estaba convertida en una verdadera marisma. En medio de una bullanga descomunal, hombres descamisados y mujeres en enaguas se perseguían y revolcaban frenéticamente en el barro o en las bateas llenas de harina y hollín dispuestas frente a los prostíbulos. . (151-152)"; "el pueblo se mostraba exultante de vida: "Desde tempranas horas del día, como ocurría siempre cada fin de semana, el pueblo de Pampa Unión comenzó a ser invadido por una bullanguera turba de mineros sedientos. Patizorros de hablar descarado, tiznados de gestos crapulosos, empleados de aire libertino y cuadrillas completas de particulares buenos para la parranda, comenzaron a colmar el pueblo por todas sus entradas de calles" (168); "nada detenía el éxodo jubiloso de esos bravos trabajadores de sol a sol hacia el único pueblo libre de la pampa, hacia el único reducto autónomo en medio de los férreos feudos salitreros que constituían cada una de las oficinas (170)". Es en esa atmósfera que irrumpe el apasionado idilio entre la delicada señorita Golondrina del Rosario, concertista y profesora de piano y aficionada a la lectura de poesía romántica, y el trompetista y crápula, Lindo Sandalio, músico de la banda del litro. . "Febrero derretía fierros esa noche. . Cuando comenzó a tocar, sus potentes fraseos de oro iluminaron de pronto la atmósfera y llenaron de sonido todo el volumen del local. .. Hacía tiempo que el trompetista no tocaba con tanta pasión. La noche era como para incendiarla de música y él, lírico de alcohol, inflamado de música, era un gitano de feria lanzando fuego por la boca. El cabaret entero guardaba silencio. . . La señorita Golondrina del Rosario, recostada sobre la cama, se había puesto a leer un libro de poemas con la ventana de su habitación abierta a la noche y a la luna. . - la brisa tibia de la noche le trajo jirones de música. Era una música de trompeta. La melodía llegó a sus oídos como un chorro de oro líquido, quemante, cósmico; como si la misma dimensión de la noche se estuviera derritiendo en pura música, en música de trompeta (112-113)". Junto al idilio, están los afanes revolucionarios del peluquero, padre de Golondrina, que planea atentar contra el Presidente. Pero todo desemboca en la muerte: la de los protagonistas, la de Pampa Unión y la de las oficinas salitreras en una visión apocalíptica que confirma la historia: "Al compás 
de la música de Chopin, cuyo dramatismo crecía a la par con el silencioso clarear del desierto, vio caer los acopios de piedras de las últimas calicheras infames, vio apagarse el humo de las usinas y morir abandonados, uno a uno, los miserables campamentos de calaminas. Junto al desmoronamiento de las casas-barracas, vio apagarse el fuego de las locomotoras, vio caer vencido el fuelle de las herrerías, vio corromperse en orín las bigornias de las maestranzas y oxidarse las terribles bateas de ripios. . . Vio los edificios de las pulperías desaparecer desmantelados, derruirse las suntuosas casas de los administradores y desbaratarse las pequeñas plazas de piedras en donde alegres orfeones de músicos dipsómanos tocaban polkas y pasodobles. . . Vio desmoronarse los techos de las filarmónicas en donde el cauchero. . . llegaba a bailar luciendo inmaculados guantes blancos. . . Como si fueran la mortaja de viejos sueños ya olvidados, vio pudrirse y desgarrarse el telón de los biógrafos. .. Vio caer desplomadas, y para siempre, las paredes de los locales de las Confederaciones Obreras en donde los trabajadores y sus mujeres acordaban sus huelgas y sus heroicas marchas de hambre a través del desierto, huelgas y marchas de hambre que al final de cuentas no les habían servido de nada sino para caer ametrallados una y otra vez en las más cruentas matanzas. . Y por último, como en un bíblico éxodo interminable y triste, vio partir a toda esa muchedumbre que un día llegara arreada en inhumanos enganches desde los distintos territorios del sur lejano... Y cuando en esa grandiosa pantalla del amanecer, la pampa entera ya no era sino un inmenso osario de oficinas muertas (301-303)". Ficción e historia se amalgaman y se funden para contar la historia de un pueblo que vivió sólo 40 años y de una cultura, la salitrera, que no pasó de los cien. Así, Pampa Unión deviene símbolo de la efímera vida de la cultura salitrera.

Pisagua y Pampa Unión: ejemplos de cómo el espacio del Norte chileno fue asumido y transformado en sucesivos paisajes y territorios, susceptibles de simbolizar un conjunto de "lugares posibles" y deconstruir un imaginario geográfico en el que se reconocen el hombre y la mujer del Norte Grande de Chile. 


\section{Obras citadas}

Arguedas, Alcides.Obras Completas. México: Aguilar, 1959.

Bachelard, Gastón.La poética del espacio. Buenos Aires: F.C.E., 2000.

Bourriaud, Nicolás. Estética relacional. Buenos Aires: Adriana Hidalgo Editora,2013.

Cornejo Polar, Antonio. Escribir en el aire. Lima: Centro de Estudios Literarios Antonio Cornejo Polar. Celacp Latinoamericana Editores, 1994.

Cullen, Gordon. El paisaje urbano. Tratado de estética urbanística, Barcelona, Editorial Blume y Editorial Labor, 1974.

Ferraro, Nicolás. Terral. Santiago: Alerce, 1959.

---. Tierramor. Antofagasta: I. de Investigaciones Antropológicas, Facultad de Educación, Universidad de Antofagasta, 1983.

Foucault, Michel. El cuerpo utópico: las heterotopías, Buenos Aires, Nueva Visión, 2010.

Lotman, Yuri. "Semiótica de la cultura". Revista Electrónica Semestral de Estudios Semióticos de la Cultura, 2003.Disponible en: http://www.ugr.es/local/mcaceres/ entretextos.htm

Missana, Sergio. Movimiento falso. Santiago: Editorial LOM, 2000.

Rivera Letelier, Hernán. Fatamorgana de amor con banda de música. Santiago: Editorial Planeta Chilena, 1999.

Slavinski, Janusz. El espacio en la literatura: distinciones elementales y evidencias introductorias. Textos y contextos. Selección y traducción por Desiderio Navarro, t. II, Editorial Arte y Literatura, La Habana, 1987: 265-287.

Teitelboim, Volodia. Pisagua. La semilla en la arena, Santiago, Editorial Quimantú, 1972. 